Potter, W. Z., Ko, G. N., Zhang, L. D., et al (1989)

Chlozapine in China: a review of US/PRC collaboration. Psychophormocology, 99. 587-\$91.

S. A. Chong, L. Chua, Woodbridge Hospital \& Institute of Mental Health, 10 Bangkok Green, Singapore 539747

\section{Citalopram-induced decreased libido}

Sir: Sexual dysfunction is a frequent but under-recognised side-effect of treatment with antidepressant drugs. It causes distress, impairs quality of life and reduces compliance with treatment. We report a case of citalopram-induced decreased libido which improved on discontinuation of the medication.

A 35-year-old man was referred with major depression of moderate severity. Despite his depression his sexual function was unimpaired. He was commenced on citalopram $20 \mathrm{mg}$ daily and his affective symptoms improved by the third week of treatment. However, 10 days after commencing citalopram he had a complete loss of interest in sex. He subsequently discontinued his medication at the end of the fourth week, after which his libido returned within seven days. He refused to resume citalopram or any other antidepressant medication for fear of further loss of libido. Because of the complete loss of libido, the effects on other aspects of sexual function could not be assessed, nor did we have an opportunity for re-challenge.

Narango et al (1987) have reported decreased libido in subjects with alcohol problems treated with citalopram, and Nyth \& Gottfries (1990) reported decreased libido induced by citalopram in elderly subjects. Citalopram is the most selective of the serotonin reuptake inhibitors. The decreased libido observed in this patient might be explained by the fact that sexual motivation and performance are inversely related to synaptic serotonin concentration (Ahlenius et al, 1989). The need to enquire about sexual function before initiation of antidepressant drugs and at subsequent follow-up cannot be over-emphasised.

Ahlenius, S., Larsson, K. \& Arviddson, L. E. (1989) Effects of steroselective $5 H T$-IA agonists on male rat sexual behaviour. Phormocology, Biochemistry and Behoviour. 33. $691-695$.

Naranjo, C. A., Sellers, E. M., Sullivan, J. T., ot al (1987) The serotonin uptake inhibitor citalopram attenuates ethanol intake. Clinical Pharmocology \& Theropeutics, 41, 266-274.
Nyth, A. L. 2 Gottfries, C. G. (1990) The clinical efficacy of citalopram in the treatment of emotional disturbances in dementia disorders. A Nordic multicentre study. British journal of Psychiatry, 157, 894-901.

A. Michael, J. J. Herrod Addenbrooke's Hospital, Cambridge CB2 2QQ

\section{Clozapine treatment, eosinophilia and agranulocytosis}

Sir: Amital et al (1997) report that initial eosinophilia in a 37-year-old man beginning clozapine treatment was followed eight weeks later by agranulocytosis and suggest a possible association.

The incidence they quote of clozapineinduced eosinophilia of $0.2-1.0 \%$ is based on spontaneous adverse event reporting and is almost certainly an underestimate. Amital et al refer to a paper by Banov et al (1993) in which an overall incidence of $14.4 \%$ is reported in a group of 118 patients. Gerlach et al (1989) have reported a survey of 354 patients starting clozapine treatment and undergoing full blood count with differential every week for the first 18 weeks of treatment. This group represents $30 \%$ of the total clozapine-treated population in Denmark between 1985 and 1987. Forty-one per cent of patients receiving clozapine as monotherapy had eosinophilia at some point. This is in close agreement with a rate of eosinophilia of $46 \%$ reported in 65 patients during up to eight weeks' clozapine treatment in a clinical trial by Claghorn et al (1987) in the USA. Hummer et al (1994) found an even higher incidence of $62 \%$ in a group of 68 Austrian patients. It is, however, surprising that, in a survey of the first 602 French patients to receive clozapine, an incidence of only $4.3 \%$ was found (Pere $e t$ al, 1992), despite weekly full blood count monitoring during the first 18 weeks.

The incidence of eosinophilia in clozapine-treated patients is, however, probably considerably higher than that of agranulocytosis. Thus, even if an association could be proven, the great majority of patients in whom a transient eosinophilia has been noted will not go on to develop an agranulocytosis; and so eosinophilia is of virtually no clinical utility in predicting clozapine-induced agranulocytosis.

Amital, D., Gross, R., Amital, H., et al (1997) Coexistence of eosinophilia and agranulocytosis in a clozapine-treated patient (letter). British journal of Psychiotry, 170, 194.
Banov, M. D., Tohen, M. \& Friedbere, J. (1993) High risk of eosinophilia in women treated with clozapine. Journal of Clinical Psychiatry, 54, 466-469.

Claghorn, J., Honigfeld, G., Abuzzahab, F. S., ot al (1987) The risks and benefits of clozapine versus chlorpromazine. Journal of Clinical Psychophormacology, 7. 377-384.

Gerlach, J., Jorgensen, E. O. \& Peacock, L. (1989) Long term experience with clozapine in Denmark: research and clinical practice. Psychopharmocology. 99(suppl.), S92-S96.

Hummer, M., Kurz, M., Barnas, C., et al (1994) Clozapineinduced transient white blood count disorders. Journal of Clinical Psychiotry, 55. 429-432.

Pere, J. J., Chaumet-Riffaud, R. D., Bourdeix, I, et al (1992) La clozapine (Leponex) en France. L'Encéphale, 18. 427-432

P. Bailey Secteur VIII Centre, Hospitalier Spécialisé, F-68250 Rauffach, France

\section{Clozapine monotherapy and ketoacidosis}

Sir: I wish to report an unusual side-effect of clozapine.

A 50-year old man with a 15-year history of DSM-IV schizophrenia was admitted to hospital with a view to a change in his medication regime. The patient had been treated with a range of neuroleptic medication with little effect on his delusions and increasingly hostile behaviour. Ten days before admission the patient received flupenthixol decanoate $80 \mathrm{mg}$ in depot form. He was also taking chlorpromazine $150 \mathrm{mg}$ every six hours, and procyclidine $5 \mathrm{mg}$ every 12 hours. On admission routine blood chemistry was normal.

He was commenced on a reducing programme of his oral medication which was stopped three days after admission. Clozapine was commenced on the fourth day of admission at a dose of $25 \mathrm{mg}$ daily. The dose was gradually increased over seven days to $100 \mathrm{mg}$ in the morning and $200 \mathrm{mg}$ in the evening.

The patient began to complain of lethargy and thirst on the tenth day after admission and shortly after developed chest pain and dyspnoea. Laboratory investigations revealed a serum blood glucose level of $23.5 \mathrm{mmol} / \mathrm{L}$. Blood gasses revealed a $\mathrm{pH}$ of 7.091 and $\mathrm{P}_{\mathrm{CO}_{2}}$ of $8.5 \mathrm{mmHg}$. A hyperkalaemia (consistent with a diagnosis of a ketoacidosis) of 4.9 was potentially lifethreatening.

Clozapine treatment was immediately suspended following confirmation with the Clozapine Patient Monitoring Service (CPMS) that at least one previous case of hyperglycaemia and ketoacidosis had been reported in the literature (Kostakoglu et al, 
1996). Eighty-one cases of diabetes have been reported following clozapine treatment worldwide (personal communication with the CPMS).

The patient improved on a regimen of subcutaneous isophane insulin.

Kostakoglu, A. E., Yazici, K. M., Erbas, T., ot al (1996) Ketoacidosis as a side-effect of clozapine: a case report. Acto Psychiotrico Scandinovico. 93, 217-218.

M. Pierides Brixton Road Community Mental Health Centre, 332 Brixton Road, London SW9 7EA

\section{Sigmund: a European database of mental health surveys}

Sir: General population studies of mental health are costly to implement and the large databanks which they produce are often under-exploited. New studies are often launched for which data are available but unknown. With the support of the European Union's BIOMED programme, we have undertaken the development of a European mental health database which centralises information on all known health surveys and general population epidemiological studies which have a mental health component. Computer software has been developed which permits us to register each study, including information such as pathologies targeted according to ICD-10 and ISIDH criteria, nature of population, financial sponsorship, time period, diagnostic criteria, instruments used, publications, accessibility and cost of data, etc.

This database may be consulted free of charge (except where extensive printouts, or copies of the original protocol are requested). Examples of the wide variety of enquiries which may be answered by Sigmund are: "Where have longitudinal studies of depression been conducted in Europe and with what age group?"; "Who has funded studies of alcoholism?"; "Is information available on child mental health in Spain and can this be accessed free of charge?"; "Which longitudinal studies of dementia have published incidence data?"; "Which instruments have been used to investigate population mental health in Greece and Italy?", and so on.

At present, 68 surveys have been registered from 11 European countries. The database is not complete and we would like to call on colleagues around Europe to send us details of any mental health studies which have been conducted in their country and are not yet registered. Any costs involved in procuring such information will be met by the databank coordination. We also invite persons for whom this utility may be of use (researchers, clinicians, policy-makers, help organisations, etc.) to consult the database freely by contacting us at the address below.

C. Polge Equipe "Vieillissement cognitif", CRLC, Val d'Aurelle, F-34298 Montepellier Cedex 5.

France. Tel: (+33)0467613028.

e-mail: catherine.polge@dicdoc.inserm.fr

\section{Influenza and schizophrenia}

Sir: I am grateful for Adams \& Kendell's (1997) agreement on the interpretation of the earlier correspondence (Crow, 1996, 1997) but I am still puzzled by the second part of their commentary. It is difficult to see how the findings of Mednick et al (1988) can be attributed to a pathogenic effect of influenza except on the basis of hypothesis (a) ("that the offspring of the entire population of women in the second trimester of pregnancy at the time of an influenza epidemic will be twice as likely to develop schizophrenia as the offspring of an unexposed population"; Adams \& Kendell, 1997). Therefore, the question arises on what basis was Adams \& Kendell's hypothesis (b) ("that the offspring of women who actually contract influenza during the second trimester of pregnancy will be twice as likely to develop schizophrenia as the offspring of women who do not") formulated? It appears to be unrelated to the original claim.

Adams, W. \& Kendell, R. E. (1997) Influenza and schizophrenia (letter). British journal of Psychiatry, 170, 578579.

Crow, T. J. (1996) Influenza and schizophrenia (letter). British Journal of Psychiotry. 169. 790-791.

- (1997) Influenza and schizophrenia (letter). British journol of Psychiotry, 170, 578.

Modnick, S. A., Machon, R. A., Huttunen, M. O., et of (1988) Adult schizophrenia following prenatal exposure to an influenza epidemic. Archives of General Psychiatry, 45, 189-192.

T. J. Crow Warneford Hospital, Headington, Oxford OX3 7jX

\section{One hundred years ago}

\section{Lunacy in London}

The London County Council has to encounter great difficulties in dealing with the yearly increasing numbers of insane patients. The Asylum Committee require to exercise skill, tact, discretion in no ordinary degree. Already the accommodation of the various asylums is overstrained, and that in spite of temporary measures. A "normal" rate of increase of 600 patients per annum is an appalling fact; but it must be faced. The whole question was considered at the Nottingham meeting of the Medico-Psychological Association, and we shall return to a consideration of the question on the publication of Dr. Rayner's paper on the "Housing of the Insane."

\section{Lunacy in Edinburgh}

Edinburgh has been called upon to consider the impossibility of continuing the present arrangements in respect of the insufficiency of the accommodation for the pauper insane. A new asylum is to be built, and an order has been issued by the General Board of Lunacy, with the approval of the Secretary for Scotland, dividing the former
Edinburgh City Lunacy District into two new districts. The pauper division of the Royal Edinburgh Asylum will thus be relieved of the pressure on its space by the removal of all patients chargeable to the parishes of Edinburgh, and will in future only receive cases from the parishes of Leith and Duddingston.

\section{REFERENCE}

journal of Mental Science. XLIII. April 1897, 426.

Researched by Henry Rollin, Emeritus Consultant Psychiatrist. Horton Hospital. Epsom. Surrey 